\title{
ABORDAGEM DA LEISHMANIOSE VISCERAL CANINA (LVC) POR MÉDICOS VETERINÁRIOS
}

\author{
Nathalia Aoun Moustapha ${ }^{1}$ \\ Esther Ligia Laura Hoffmann Bueno Magdanelo ${ }^{1}$ \\ Júlia Negrão Multari ${ }^{1}$ \\ Giovanna Tellaroli ${ }^{1}$ \\ Ed Wilson Santos ${ }^{2}$
}

\section{RESUMO}

A Leishmaniose visceral canina (LVC) é uma zoonose de extrema importância na saúde pública, de distribuição mundial, com $90 \%$ dos casos registrados no Brasil. É causada pelo protozoário gênero Leishmania e tem como principal hospedeiro o cão doméstico. Para que ocorra a transmissão, é obrigatória a presença do vetor hematófago Lutzomyia longipalpis. $\mathrm{O}$ diagnóstico da doença é bastante difícil, já que 60 a $80 \%$ dos animais soropositivos são assintomáticos e as manifestações clínicas são muito inespecíficas. Após mudanças realizadas pelo Ministério da Saúde, atualmente é permitido realizar o tratamento dos animais positivos para LVC, no qual o medicamento mais aceito é a miltefosina, porém, independente do tratamento, o melhor método contra a LVC é a prevenção. No presente trabalho foi produzido um questionário através da plataforma Google Forms com 14 perguntas englobando a Leishmaniose. Foram coletadas 65 respostas de médicos veterinários de diferentes idades e estados do Brasil. $80 \%$ dos veterinários disseram indicar o tratamento do animal em caso de leishmaniose confirmada, enquanto 3,08\% ainda indicam a eutanásia. Embora não recomendados, ainda se nota o uso de anfotericina $\mathrm{B}$ e antimoniais pentavalentes nos protocolos de tratamento, porém a maioria (75,4\%) opta pelo uso da miltefosina, recomendada. A vacinação, embora aceita pela maioria dos veterinários $(95,38 \%)$, ainda é uma prática pouco utilizada devido à baixa disponibilidade do produto nas clínicas, somente $47,69 \%$ tem no consultório. Dentre os veterinários, 95,4\% indicam o uso de coleiras de deltametrina como prevenção. Uma boa atuação do médico veterinário é de suma importância para o efeito controle da LVC.

Palavras-chave: leishmaniose visceral canina; Brasil; tratamento; prevenção; controle.

\section{APPROACH TO CANINE VISCERAL LEISHMANIASIS (CVL) BY VETERINARY DOCTORS}

\begin{abstract}
The canine visceral leishmaniasis (CVL) is a zoonosis extremely important for public health, of worldwide relevance, with $90 \%$ of the cases registered in Brazil. It's caused by the protozoan from the genus Leishmania and its main host is the domestic dog. For the successful transmission, it must have the presence of the vector Lutzomyia longipalpis. The diagnostic from this disease is extremely difficult, seen that $60 \%$ to $80 \%$ of the seropositive animals are asymptomatic and the clinical manifestations are very nonspecific. After changes made by the Health Ministry, it actually is permitted to realize the treatment of the positive animals to CVL, in which the most accepted medicament is Miltefosine. Yet, independent of
\end{abstract}

\footnotetext{
${ }^{1}$ Discente da Faculdade de Medicina Veterinária na Universidade Anhembi Morumbi

${ }^{2}$ Docente da Faculdade de Medicina Veterinária na Universidade Anhembi Morumbi
} 
the treatment, the best method against CVL is prevention. In the present study was produced a questionnaire through the platform Google Forms with 14 questions encompassing the Leishmaniasis. Were collected 65 answers of veterinarians of different ages and states of Brazil. $80 \%$ of vets said to indicate the treatment of the animal in cases of leishmaniasis confirmed, while $3.08 \%$ still indicate euthanasia. Although not recommended, the use of amphotericin B and pentavalent antimonials is still seen in the treatment protocols, however, the majority (75.4\%) opts for the use of Miltefosina, recommended. Vaccination, although accepted by most veterinarians $(95.38 \%)$, is still a little-used practice due to the low product availability in clinics, just $47.69 \%$ have in the veterinary clinic. Among veterinarians, $95.4 \%$ indicate the use of deltamethrin collars as prevention. A good performance by the veterinarian is very importance for the control effect of CVL.

Keywords: canine visceral leishmaniasis; Brazil; treatment; prevention; control.

\section{ENFOQUE DE LA LEISHMANIASIS VISCERAL CANINA (LVC) POR DOCTORES VETERINARIOS}

\section{RESUMEN}

La leishmaniasis visceral canina (LVC) es una zoonosis de extrema importancia en la salud pública, en todo el mundo, con el 90\% de los casos registrados en Brasil. Es causada por el protozoario género Leishmania y su principal huésped es el perro doméstico y, para que se produzca la transmisión, es obligatoria la presencia del vector Lutzomyia longipalpis. El diagnóstico de la enfermedad es bastante difícil, ya que del 60 al $80 \%$ de los animales seropositivos son asintomáticos y las manifestaciones clínicas son muy inespecíficas. Después de los cambios realizados por el Ministerio de Salud, actualmente está permitido llevar a cabo el tratamiento de animales positivos para LVC, en el que el medicamento más aceptado es Miltefosina, sin embargo, independientemente del tratamiento, el mejor método contra LVC es la prevención. En el presente trabajo, se produjo un cuestionario a través de la plataforma Google Forms con 14 preguntas que cubren la leishmaniasis. Se recogieron 65 respuestas de veterinarios de diferentes edades y estados de Brasil. El 80\% de los veterinarios dijeron que indicaban el tratamiento del animal en caso de leishmaniasis confirmada, mientras que el 3.08\% todavía indica eutanasia. Aunque no se recomienda, aún se observa el uso de anfotericina $\mathrm{B}$ y antimoniales pentavalentes en los protocolos de tratamiento, sin embargo, la mayoría (75.4\%) opta por el uso de miltefosina, se recomienda. La vacunación, aunque aceptada por la mayoría de los veterinarios $(95.38 \%)$, todavía es una práctica poco utilizada debido a la baja disponibilidad del producto en las clínicas, solo el $47.69 \%$ lo tiene en la clínica veterinaria. Entre los veterinarios, el 95.4\% indica el uso de collares de deltametrina como prevención. Un buen desempeño por parte del veterinario es de suma importancia para el efecto de control de LVC.

Palabras clave: leishmaniasis visceral canina; Brasil; tratamiento; prevención; controlar.

\section{INTRODUÇÃO}

A leishmaniose visceral (LV) é uma doença potencialmente fatal, de distribuição mundial em 76 países e 12 deles na América Latina, sendo que 90\% dos casos ocorrem no Brasil, onde também é conhecida como calazar $(1,2)$. Era considerada uma doença esporádica, mas ao longo dos anos, houve mudança neste cenário, adquirindo uma grande importância e passando a ser considerada uma doença de notificação compulsória $(3,4)$. 
No Brasil, até nos anos 90, quase a totalidade de casos estava concentrada na região rural do Nordeste, considerada área endêmica. Porém, se apresenta em franca expansão por todos estados mais ao sul, devido a urbanização e fluxo migratório $(1,3,5)$. Em 1998, em São Paulo, ocorreu uma epidemia na região de Araçatuba, que depois veio a se disseminar por outras regiões em decorrência da circulação de cães infectados (6). No período de 2003 a 2018, foram confirmados mais de 51 mil casos humanos, com incidência média de 1,7 casos/100 mil habitantes e letalidade de 7,2\%. As regiões Norte e Nordeste apresentam o maior número de casos (7).

Essa doença é uma zoonose provocada por um protozoário da ordem Kinetoplastida, família Trypanosomatidae, e gênero Leishmania, tendo a $L$. chagasi como a principal causadora da forma clínica da LV na América Latina. Apresentam-se na forma de parasitas intracelulares obrigatórios, na sua forma amastigota, arredondada e sem flagelo. As promastigotas, com longo flagelo são encontradas tubo digestório do vetor $(5,6,8)$.

Os reservatórios são essenciais para a manutenção da doença no ambiente. Na área urbana, o cão doméstico (Canis familiaris), é a principal fonte que precede a infecção humana. Já no ambiente silvestre, as raposas (Dusicyon vetulus), cachorro-do-mato (Cerdocyon thous) e marsupiais (Didelphis albiventris) $(1,5)$.

Para que ocorra a transmissão é obrigatória a presença do vetor, animal invertebrado, tendo como principal na LV a fêmea de flebotomídeos, dípteros hematófagos da família Psychodidae, subfamília Phebotomie e gênero Lutzomyia, principalmente a espécie Lutzomyia longipalpis (1).

A infecção ocorre durante o repasto sanguíneo, pela introdução das formas promastigotas da Leishmania presentes no vetor. Na corrente sanguínea, as promastigotas são fagocitadas por macrófagos, onde se transformarão em amastigotas e ocorrerá sua multiplicação, causando a morte celular por rompimento e liberando assim novas formas amastigotas. Estas poderão migrar para linfonodos, baço, fígado, medula óssea e áreas dérmicas, causando uma infecção sistêmica (10).

\section{Diagnóstico}

O diagnóstico clínico da leishmaniose visceral canina (LVC) é de grande desafio, já que em torno de 60 a $80 \%$ dos animais soropositivos são assintomáticos, e os que desenvolvem, podem apresentar sinais muito inespecíficos e comuns em outras patologias.

O diagnóstico pode ser por reação de imunofluorescência indireta (RIFI) ou ensaio imunoenzimático (ELISA). Pode acontecer baixa detecção de anticorpos, indicando início da infecção, antes da soroconversão, que possui variação de 94 dias até um ano em cães infectados $(1,11,12)$.

Um método comum é realizar a pesquisa parasitológica por punção de órgãos, que possibilita visualizar o parasita através do aspirado de medula óssea, baço, linfonodo ou biópsia de fígado ou pele. Este método possui especificidade de quase $100 \%$, porém sensibilidade variável, uma vez que a distribuição do parasita não é homogênea, podendo gerar falso negativo, principalmente em cães assintomáticos $(11,13)$.

Existe ainda o diagnóstico pela imunohistoquímica (IHQ), que possui uma sensibilidade mais elevada que a pesquisa parasitológica por punção, pois possibilita a detecção do parasita mesmo em baixa carga parasitária. Possui sensibilidade de $73,9 \%$ em cães assintomáticos, chegando a $98,51 \%$ em cães sintomáticos $(11,14)$.

Por fim, o diagnóstico molecular pela reação em cadeia de polimerase (PCR), por meio de aspirados de medula óssea e linfonodos, sangue e urina. Possui sensibilidade variável dependendo da amostra (11). Segundo Queiroz (12) a técnica de PCR por amostras de pele foi

Moustapha NA, Magdanelo ELLH, Multari JN, Tellaroli G, Santos, EW. Abordagem da leishmaniose visceral canina (LVC) por médicos veterinários. Vet. e Zootec. 2021; v28: 001-012. 
$100 \%$ sensitiva nos animais, pois já foi revelado a presença de parasitas em peles clinicamente saudáveis, independente da manifestação clínica.

\section{Tratamento e prevenção}

O tratamento da LVC no Brasil é um tema bastante delicado. Em 2008, a Portaria Interministerial $\mathrm{n}^{\circ} 1.426$, proibiu o tratamento da leishmaniose visceral canina com produtos de uso humano ou não registrados no MAPA (Ministério da Agricultura, Pecuária e Abastecimento), considerando que não havia eficácia terapêutica, muito menos redução do risco de transmissão, podendo induzir seleção de cepas resistentes aos medicamentos disponíveis (15), sendo mantido em 2009 no II Fórum de discussão sobre o tratamento da LVC, a proibição do tratamento com medicações humanas (16). Como medicamentos humanos são citados os antimoniais, anfotericina B e suas formulações lipossomais (1).

O Ministério da Saúde não recomenda o tratamento dos cães positivos, pois podem não mais apresentarem sintomas clínicos, mas continuam agindo como reservatórios, passíveis de transmissão, sendo indicada a eutanásia para controle da doença. Portanto, o melhor método contra a LVC é a prevenção, através de saneamento ambiental, limpeza urbana, eliminação de resíduos orgânicos a fim de evitar e reduzir a proliferação do vetor. O uso de coleiras impregnadas de Deltametrina 4\% como proteção individual para evitar picadas, além do uso de telas em canis individuais ou coletivos, clínicas veterinárias, abrigos e residências para evitar a entrada dos flebotomíneos também é usado para diminuir a transmissão $(1,17)$.

A vacinação é, sem dúvida, um importante método preventivo. Atualmente apenas a Leish-Tec ${ }^{\circledR}$ tem registro no MAPA. O protocolo de três aplicações com intervalo de 21 dias a partir de quatro meses de vida e reforço anual costuma ser preconizado (17). Em Novembro de 2014, o MAPA suspendeu a licença de fabricação e comercialização da vacina Leishmune ${ }^{\circledR}$, da Zoetis Saúde Animal, por ter descumprido o Regulamento Técnico para Pesquisa, Desenvolvimento, Produção, Avaliação, Registro e Renovação de Licença, Comercialização e Uso de Vacina contra Leishmaniose Visceral Canina (18).

Segundo a Resolução do CFMV n ${ }^{\circ}$ 1.000, de 11 de maio de 2012, os animais diagnosticados, mesmo assintomáticos devem ser submetidos à eutanásia por órgãos da saúde pública. No entanto, em 2016, na Nota Técnica Conjunta nº 001/2016 MAPA/MS, abriu-se a possibilidade de tratamento do animal portador da LVC, sendo orientado por um médico veterinário e medicamentos exclusivos para esse fim (19-23).

Apenas um medicamento no Brasil cumpre tal determinação, o Milteforan ${ }^{\circledR}$, cujo princípio ativo é a miltefosina, de propriedade da empresa Virbac Saúde Animal $(4,18,24)$. Possui custo muito elevado, dificultando o tratamento de acordo com a condição socioeconômica e cultural das regiões atingidas (25). Ela permite inibição do crescimento das formas promastigotas e provoca morte das amastigotas, resultando assim intensa atividade leishmanicida.

Um tratamento de 28 dias consecutivos de miltefosina, diminui significativamente a carga parasitária, com melhora dos sinais clínicos, mas sem a resolução total do caso clínico (26).

Considerando a leishmaniose visceral uma doença com grande importância de saúde pública, grave e que pode levar a óbito quando não tratada, além da dificuldade de diagnóstico e tratamento, este trabalho tem como objetivo conhecer o método diagnóstico e os protocolos de tratamento escolhidos por veterinários no Brasil, com vistas à preservação da espécie animal, como também a proteção da saúde e vidas humanas. 


\section{MATERIAIS E MÉTODOS}

Para a realização do presente trabalho, foi produzido um questionário (Anexo 1) através da plataforma Google Forms com 14 perguntas englobando a Leishmaniose. O período compreendido para aplicação do questionário foi de um mês, sendo coletadas respostas de 65 médicos veterinários de diferentes idades e estados do Brasil.

O formulário continha uma parte inicial para identificação do médico veterinário e, em seguida, questões sobre métodos diagnósticos utilizados, comunicação de autoridades, indicação para realização do tratamento ou eutanásia em casos positivos, qual tratamento instituído, orientações de medidas preventivas e vacinação de animais, frequência de acompanhamento dos casos e exames solicitados.

\section{RESULTADOS}

No período compreendido entre 31 de março a 02 de maio de 2020, foram aplicados os 65 questionários e $73,85 \%$ dos entrevistados tinham entre 20 a 35 anos, seguido de $24,6 \%$ entre 35 a 50 anos e apenas 1,5\% com idade entre 51 a 65 anos. 50,76\% deles atuam no estado de São Paulo, 20\% no Distrito federal, 4,61\% em Minas Gerais. Os outros 24,52\% são formados por profissionais de Santa Catarina, Pará, Maranhão, Pernambuco, Rio Grande do Sul, Rio Grande do Norte, Mato Grosso do Sul, Bahia, Piauí e Amazonas.

Os principais métodos diagnósticos escolhidos pelos veterinários entrevistados foram o PCR e o ELISA (Tabela 1).

Tabela 1. Resultados da escolha de métodos diagnósticos para LVC dentre os 65 entrevistados.

\begin{tabular}{lcc}
\hline Métodos Diagnóstico & Número absoluto & Percentagem (\%) \\
\hline PCR & 53 & 81,5 \\
ELISA & 50 & 76,9 \\
RIFI & 41 & 63,1 \\
Punção aspirativa de nódulo & 45 & 69,2 \\
Citologia & 39 & 60,0 \\
Biópsia & 29 & 44,6 \\
Histopatológico & 21 & 32,2 \\
Escarificação & 2 & 3,1 \\
Isolamento do parasita & 0 & 0 \\
\hline
\end{tabular}

Fonte: Resultado da pesquisa.

Apesar de ser uma zoonose de notificação compulsória, após a confirmação do caso, apenas 64,62\% dos veterinários dizem comunicar às autoridades (Figura 1). 


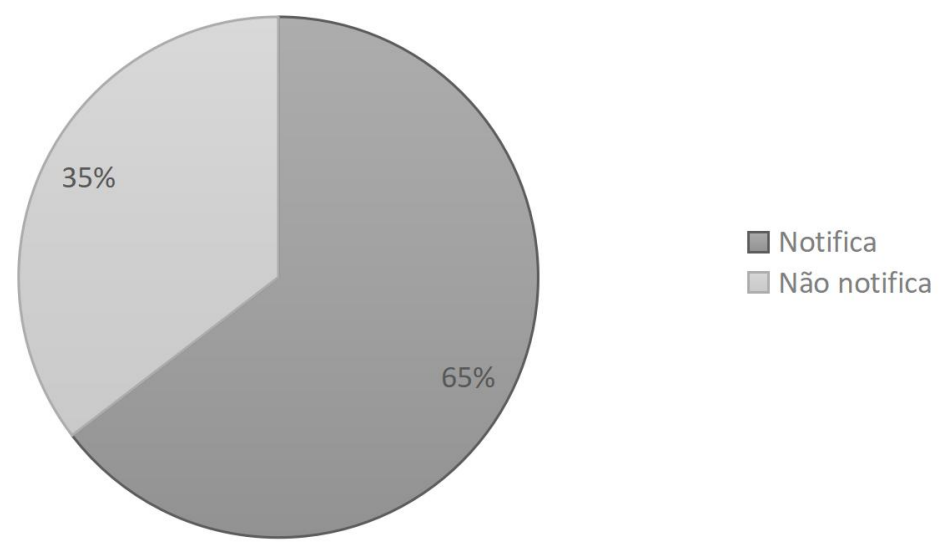

Figura 1 - Notificação a autoridades em casos positivos da LVC Fonte: Resultado da pesquisa.

Segundo dados coletados, $80 \%$ dos veterinários disseram indicar o tratamento do animal em caso de leishmaniose confirmada. Apenas 3,08\% indicam a eutanásia nesses casos. Os outros 16,92\% dizem avaliar o caso individualmente, indicando tratamento ou eutanásia dependendo da condição do animal, do tutor ou ainda encaminham o caso para o clínico geral.

A escolha do tratamento baseada no nível socioeconômico do tutor diz ser uma realidade para 53,85\% dos veterinários e $80 \%$ confirmaram a escolha de acordo com a responsabilidade do tutor e presença nas consultas.

A miltefosina, o alopurinol e a realização de medicações suporte foram as mais selecionadas dentre as opções de tratamento, dos veterinários. A anfotericina $\mathrm{B}$, também indicada para tratamento de Leishmaniose em humanos, apesar de ser contraindicado o uso de medicamentos humanos para tratamento de leishmaniose em cães (Tabela 2).

Tabela 2. Percentagem dos resultados da escolha do tratamento para LVC

\begin{tabular}{lcc}
\hline Métodos Diagnóstico & Número absoluto & Percentagem (\%) \\
\hline Miltefosina & 49 & 75,4 \\
Alopurinol & 44 & 67,7 \\
Anfotericina B & 6 & 9,2 \\
Antimoniais pentavalentes & 5 & 7,7 \\
Marbofloxacina & 39 & 16,9 \\
Aminosidina & 1 & 1,5 \\
Tratamento suporte & 48 & 73,8 \\
\hline
\end{tabular}

Fonte: Resultado da pesquisa.

Quanto aos métodos preventivos, a grande maioria $(95,4 \%)$ dos veterinários indicam o uso de coleira de deltametrina. Apenas 55,4\% optam pelo uso de inseticidas para o controle do vetor da doença e $69,2 \%$ indicam a telagem de janelas. 
Como prevenção aos contactantes dos animais portadores de leishmaniose, 95,38\% dizem indicar a vacinação. Esta, por sua vez é utilizada, por sua forma comercial, Leish-Tec ${ }^{\circledR}$ por $86,15 \%$ e apenas $9,23 \%$ indicam a Leishmune ${ }^{\circledR} .4,61 \%$ não indicam a vacinação nos animais. 52,31\% dos entrevistados afirmaram não ter a vacina contra a leishmaniose no consultório que trabalham.

Quanto a rotina de retornos, 59 dos $65(90,77 \%)$ veterinários afirmaram a realização de consultas periódicas. Dentre os 59, 56 responderam essa pergunta, o que foi constatado que $12,5 \%$ acompanham o paciente a cada 6 a 12 meses; $17,85 \%$ preferem consultas de 2 a 3 meses, 32,14\% optam por consultas mensais e 21,42\% agendam entre 1 a 3 semanas. $\mathrm{O}$ restante, $10,71 \%$, diz avaliar cada caso individualmente e agendar conforme necessidade. $5,35 \%$ não sabe informar pois nunca atendeu ou acompanha o caso após diagnóstico.

Os exames para acompanhamento do quadro são solicitados pela maioria $(98,5 \%)$. A função renal está como o exame mais solicitado, sendo escolhido por $96,9 \%$ dos entrevistados, seguido da função hepática e do hemograma completo, com 93,8\% e 95,4\% das solicitações, respectivamente. A pesquisa parasitológica é solicitada por $58,5 \%$ e apenas $1,5 \%$ dizem não solicitar exames.

\section{DISCUSSÃO}

Os dados coletados pelo questionário mostraram que, para o desafiador diagnóstico clínico de Leishmaniose visceral canina (LVC), de grande importância tanto para fins de controle como para fins de definição de áreas com maior risco de transmissão da doença, a maioria dos entrevistados, $81,5 \%$, utiliza o PCR como método, o que vai de encontro ao descrito por Queiroz (12), sendo uma técnica de alta sensibilidade e pouco invasiva (18).

Embora apresente grande número de casos falso negativos devido reações cruzadas ou realização do exame antes da soroconversão $(11,19)$, a sorologia ELISA também foi um método bastante escolhido, sendo selecionado por $76 \%$ dos entrevistados.

Ainda que sejam "teste-ouro" para diagnóstico definitivo, já que são visualizadas as formas amastigotas microscopicamente, os métodos mais invasivos, como biópsia $(44,6 \%)$ e o histopatológico $(32,3 \%)$ foram os menos escolhidos dentre os selecionados para o diagnóstico devido a maior dificuldade e risco em sua realização somada a variável sensibilidade, principalmente em cães assintomáticos $(11,13,19)$. A punção aspirativa de nódulo e a citologia também são escolhas diagnóstica de $69,2 \%$ e $60 \%$ dos veterinários entrevistados, respectivamente.

Nenhum veterinário optou pelo método de isolamento do parasita em meio de cultura ou IMIQ, também realizados com amostras de fígado, baço, medula óssea e linfonodos. Isso se deve, provavelmente, ao longo prazo de espera pela obtenção do resultado e sua baixa sensibilidade, principalmente nas fases iniciais da doença (19).

A notificação de casos suspeitos ou confirmados de LVC é necessária para mapeamento de regiões endêmicas e controle de reservatórios. Orienta-se o preenchimento de um formulário municipal para notificação da zoonose. Dentre os entrevistados, apenas $64,62 \%$ afirma essa prática (21).

O tratamento da LVC no Brasil deve obedecer ao disposto na Portaria Interministerial $n^{\text {o }}$ 1.426/2008, dos Ministérios da Saúde e MAPA (18,22). Faz parte da Portaria interministerial citada que o tratamento medicamentoso de cães só será permitido desde que não sejam utilizados medicamentos de humanos, como os antimoniais, anfotericina $\mathrm{B}$ e suas formulações lipossomais (1). A indicação de tratamento aos casos confirmados é feita por $80 \%$ dos veterinários, 3,08\% indicam a eutanásia nesses casos.

Dentre as opções de tratamento presentes no formulário, a miltefosina $(74,5 \%)$, o alopurinol $(67,7 \%)$ e a realização de medicações suporte $(73,8 \%)$ foram as mais selecionadas.

Moustapha NA, Magdanelo ELLH, Multari JN, Tellaroli G, Santos, EW. Abordagem da leishmaniose visceral canina (LVC) por médicos veterinários. Vet. e Zootec. 2021; v28: 001-012. 
Apesar da proibição, a Anfotericina B e os Antimoniais pentavalentes, indicada para tratamento de leishmaniose em humanos, foram escolhidos por $9,2 \%$ e $7,7 \%$ dos entrevistados, respectivamente.

O uso de antibióticos, marbofloxacina e aminosidina, também foram referidos, respectivamente, por $16,9 \%$ e $1,5 \%$. A marbofloxacina tem atividade leishmanicida por meio da inibição da enzima DNAgirase do parasita e do estímulo de produção do TNF- $\alpha$. O protocolo de tratamento utilizado é de $2 \mathrm{mg} / \mathrm{kg}$ uma vez ao dia por 28 dias, podendo tornar-se uma boa opção em associação a outros tratamentos (27).

A aminosidina, por sua vez, é um antibiótico aminoglicosídeo de amplo espectro, que atua por inibição da síntese proteica na Leishmania (17).

A prevenção da doença nos cães e a proteção de humanos e outros animais que convivem com cães portadores consiste principalmente no uso de coleiras de Deltametrina 4\%, já que evitam as picadas dos flebotomídeos $(1,18)$. Este método preventivo foi escolhido pela grande maioria dos entrevistados, 95,4\%. Como controle químico dos vetores também se opta pelo uso de inseticidas $(55,4 \%)$.

A vacina para cães contra a Leishmaniose atualmente disponível e aprovada pelo MAPA, embora não tenha eficácia comprovada quanto a redução da incidência da leishmaniose visceral em humanos, não sendo assim preconizada pelo Ministério da Saúde, tem seu uso indicado para proteção individual dos cães $(19,28)$. A vacinação foi indicada por, $95,38 \%$ sendo Leish-Tec ${ }^{\circledR}$ por $86,15 \%$ e apenas $9,23 \%$ a Leishmune ${ }^{\circledR}$. Lembrando que a Leishmune não possui registro aprovado pelo MAPA.

Como impeditivo para realização da vacinação está a disponibilidade da mesma, uma vez que $52,31 \%$ dos entrevistados afirmaram não ter a vacina disponível no consultório que trabalham, não sendo assim orientadas aos proprietários.

É imprescindível que se cumpra o protocolo de tratamento instituído pelo médico veterinário, respeitando-se a necessidade de reavaliação clínica, laboratorial e parasitológica periódica, a necessidade de realização de novo ciclo de tratamento e as medidas preventivas (19). Este controle deve ser rigoroso, sendo que 90,77\% dos veterinários afirmaram a realização dessas consultas periódicas e realização de exames laboratoriais $(98,5 \%)$, sendo escolhidos principalmente hemograma, função renal e hepática. A pesquisa parasitológica de acompanhamento é feita por apenas 58,5\%. Sugere-se intervalos a cada 3 meses no primeiro ano, intervalos de 4 meses no segundo e de 6 meses após o terceiro ano de tratamento (29).

\section{CONCLUSÃO}

A complexidade de fatores de transmissão dessa antropozoonose é de grande desafio, sendo um grave problema de saúde pública. Uma boa atuação do médico veterinário é de suma importância para o efeito controle da LVC. Mesmo com a notificação compulsória, podemos notar que nem todos notificam as autoridades responsáveis.

Atualmente, é possível optar pela escolha do tratamento medicamentoso ao invés da eutanásia dos animais portadores, sendo confirmada essa prática pela maioria dos veterinários entrevistados. Embora não recomendadas para o tratamento em animais, ainda se nota o uso de anfotericina B e antimoniais pentavalentes. A maioria opta pelo uso da miltefosina, recomendada. A vacinação, embora aceita pela maioria dos veterinários, ainda é uma prática pouco utilizada devido à baixa disponibilidade do produto nas clínicas.

\section{REFERÊNCIAS}

1. Brasil. Ministério da Saúde. Secretaria de Vigilância em Saúde. Departamento de Vigilância Epidemiológica. Manual de vigilância e controle da leishmaniose visceral

Moustapha NA, Magdanelo ELLH, Multari JN, Tellaroli G, Santos, EW. Abordagem da leishmaniose visceral canina (LVC) por médicos veterinários. Vet. e Zootec. 2021; v28: 001-012. 
[Internet]. Brasília: Ministério da Saúde; 2014 [citado 20 Abr 2021]. Disponível em: http://www.saude.ba.gov.br/wp-content/uploads/2019/05/2014-Manual-devigil $\% \mathrm{C} 3 \% \mathrm{~A} 2$ ncia-e-controle-da-leishmaniose-visceral.pdf

2. Organização Mundial da Saúde - OMS, Organização Pan-Americana da Saúde - OPAS. Leishmanioses informe epidemiológico das américas [Internet]. Washington: OMS, OPAS; 2018 [citado 20 Abr 2021]. Disponível em: https://iris.paho.org/bitstream/handle/10665.2/34857/LeishReport6_por.pdf?sequence=5\&i $\underline{\text { sAllowed }=y}$

3. Alves WA, Bevilacqua PD. Quality of diagnosis of canine visceral leishmaniasis in epidemiological surveys: an epidemic in Belo Horizonte, Minas Gerais, Brazil, 1993-1997. Cad Saude Publica [Internet]. 2004 [citado 20 Abr 2021];20(1):259-65. Disponível em: http://www.scielo.br/scielo.php?script=sci arttext\&pid=S0102$\underline{311 X 2004000100043 \& \operatorname{lng}=\text { en }}$

4. Albuquerque ALH, Langoni $\mathrm{H}$. A prática do tratamento na leishmaniose visceral canina (LVC) em clínicas veterinárias, cuidados e protocolos. Vet Zootec [Internet]. 2018 [citado 20 Abr 2021];25(1):132-41. Disponível em: https://rvz.emnuvens.com.br/rvz/article/view/23

5. Aguiar PF, Rodrigues RK. Leishmaniose visceral no Brasil: artigo de revisão. Unimontes Cient [Internet]. 2017 [citado 20 Abr 2021];19(1):191-204. Disponível em: http://www.ruc.unimontes.br/index.php/unicientifica/article/view/526

6. Galvão ALB, Nardo CDD, Atique Neto H, Benitez NA, Ribeiro CR, Bresciani KDS, et al. Capacitação de equipes para inquérito sorológico canino para pesquisa de leishmaniose. Arch Vet Sci [Internet]. 2019 [citado 20 Abr 2021];24(2):73-80. Disponível em: https://revistas.ufpr.br/veterinary/article/view/62293

7. Brasil. Ministério da Saúde. Secretaria de Vigilância em Saúde. Vigilância em saúde no Brasil 2003|2019: da criação da Secretaria de Vigilância em Saúde aos dias atuais. Bol Epidemiol [Internet]. 2019 [citado 20 Abr 2021];50(esp):1-154. Disponível em: http://www.saude.gov.br/ boletins-epidemiologicos

8. Mansour CEK. Investigação e documentação de flagelados no tubo digestório de flebotomíneos [dissertação]. São Paulo: Faculdade de Medicina Veterinária e Zootecnia, Universidade de São Paulo; 2018. doi: 10.11606/D.6.2018.tde-05092018-150718.

9. Missawa NA, Lorosa ES, Dias ES. Preferência alimentar de Lutzomyia longipalpis (Lutz \& Neiva, 1912) em área de transmissão de leishmaniose visceral em Mato Grosso. Rev Soc Bras Med Trop [Internet]. 2008 [citado 20 Abr 2021];41(4):365-8. Disponível em: https://www.scielo.br/scielo.php?pid=S0037-86822008000400008\&script=sci_abstract\&tlng=pt

10. Lopes UL. Leishmaniose visceral canina: relato de caso [trabalho de conclusão de curso] [Internet]. Garanhuns (PE): Unidade Acadêmica de Garanhuns, Universidade Federal Rural de Pernambuco; 2019 [citado 20 Abr 2021]. Disponível em: http://hdl.handle.net/123456789/1573 
11. Costa GP, Silva PC, Rocha DOAC, Teixeira PHG. Métodos de diagnóstico da leishmaniose canina: revisão de literatura. Rev Saber Cient. 2020;9(2):95-104. doi: http://dx.doi.org/10.22614/resc-v9-n2-1375.

12. Queiroz NMGP, Assis J, Oliveira TMFS, Machado RZ, Nunes CM, Starke-Buzetti WA. Diagnóstico da Leishmaniose Visceral Canina pelas técnicas de imunoistoquímica e PCR em tecidos cutâneos em associação com a RIFI e ELISA-teste. Rev Bras Parasitol Vet [Internet]. 2010 [citado 20 Abr 2021];19(1):32-8. Disponível em: https://www.scielo.br/scielo.php?script=sci arttext\&pid=S1984-29612010000100007

13. Sundar S, Rai M. Laboratory diagnosis of visceral leishmaniasis. Clin Diagn Lab Immunol. 2002;9(5):951-8.

doi: 10.1128/CDLI.9.5.951-958.2002.

14. Guerra JM, Fernandes NCCA, Kimura LM, Shirata NK, Magno JA, Abrantes MF, et al. Avaliação do exame imuno-histoquímico para o diagnóstico de Leishmania spp. em amostras de tecidos caninos. Rev Inst Adolfo Lutz [Internet]. 2016 [citado $20 \mathrm{Abr}$ 2021];75:1686. Disponível em: https://pesquisa.bvsalud.org/portal/resource/pt/ses-34210

15. Donato LE, Lima Júnior FEF, Alburquerque R, Gomes MLS. Vigilância e controle de reservatórios da leishmaniose visceral no Brasil: aspectos técnicos e jurídicos. Rev Educ Contin Med Vet Zootec CRMV-SP [Internet]. 2013 [citado 20 Abr 2021];11(2):18-3. Disponível em: crmvsp.com.br/index.php/recmvz/article/view/16219

https://www.revistamvez-

16. Brasil. Ministério da Saúde. Secretaria de Vigilância em Saúde. II Fórum de discussão sobre o tratamento da Leishmaniose Visceral Canina (LVC) [Internet]. Brasília: Ministério da Saúde; 2009 [citado 20 Abr 2021]. Disponível em: https://www.paho.org/bra/index.php?option=com_content\&view=article\&id=3909:1eish $\underline{\text { maniose-visceral-canina-forum-de-discussao-sobre-tratamento-2\&Itemid }=812}$

17. Brasil. Conselho Federal de Medicina Veterinária - CFMV. Comissão Nacional de Saúde Pública Veterinária. Guia de bolso leishmaniose visceral [Internet]. Brasília: CFMV; 2020 [citado 20 Abr 2021]. Disponível em: https://www.crmvsp.gov.br/arquivo comissoes/guiabolso-leishmaniose_v2.pdf

18. Brasil. Conselho Federal de Medicina Veterinária - CFMV. Medicamento para tratamento de LVC deve ser emitido somente via SIPEAGRO [Internet]. Brasília: CFMV; 2020 [citado 20 Abr 2021]. Disponível em: http://portal.cfmv.gov.br/noticia/index/id/5996/secao/6

19. Nogueira FDS, Ribeiro VM. Leishmaniose visceral. In: Jericó M, Andrade Neto JPD, Kogika, MM. Tratado de medicina interna de cães e gatos. Rio de Janeiro: Roca; 2015. p.718-31.

20. Costa DNCC, Codeço CT, Bermudi PMM, Rodas LAC, Nunes CM, Hiramoto RM, et al. Controle da leishmaniose visceral canina por eutanásia: estimativa de efeito baseado em inquérito e modelagem matemática. Cad Saude Publica. 2020;36(2):e00221418. doi: https://doi.org/10.1590/0102-311X00221418. 
21. Prefeitura da Cidade de São Paulo. Leishmaniose visceral canina - Ficha de notificação [Internet]. São Paulo; 2018 [citado 20 Abr 2021]. Disponível em: https://www.prefeitura.sp.gov.br/cidade/secretarias/upload/saude/Ficha\%20Suspeita $\% 20$ de\%20LeishmanioseJunho2018.pdf

22. Brasil. Ministério da Saúde. Nota informativa [Internet]. Brasília: Ministério da Saúde; 2016 [citado 20 Abr 2021]. Disponível em: http://www.saude.gov.br/images/pdf/2016/setembro/23/NT-informativa-Milteforan--002$\ldots$..pdf

23. Brasil. Ministério da Agricultura, Pecuária e Abastecimento. Nota técnica [Internet]. Brasília: MAPA; 2016 [citado 20 Abr 2021]. Disponível em: http://www.sbmt.org.br/portal/wp-content/uploads/2016/09/nota-tecnica.pdf

24. Organización Panamericana de la Salud. Leishmaniasis en las américas: recomendaciones para el tratamiento [Internet]. Washington: OPAS; 2014 [citado 20 Abr 2021]. Disponível em: http://www.saude.gov.br/images/pdf/2014/julho/18/Leishmanioses-nasAm--ricas-recomenda----es-para-o-tratamento.pdf

25. Gontijo CMF, Melo MN. Leishmaniose visceral no Brasil: quadro atual, desafios e perspectivas. Rev Bras Epidemiol [Internet]. 2004 [citado 20 Abr 2021];7(3):338-49. Disponível em: $\quad$ https://www.scielo.br/scielo.php?pid=S1415$\underline{790 X 2004000300011 \& \text { script }=\text { sci_arttext }}$

26. Lisboa JCL, Urzulin HA, Araujo KS, Santana MA, Bento SGR, Nogueira FS. Acompanhamento clínico e laboratorial de cães parasitologicamente positivos para leishmaniose visceral submetidos à terapia com miltefosina associada ao alopurinol. Rev Educ Contin Med Vet Zootec CRMV-SP [Internet]. 2018 [citado 20 Abr 2021];16(3):7980. Disponível em: https://www.revistamvezcrmvsp.com.br/index.php/recmvz/article/view/37829

27. Rougier S, Vouldoukis I, Fournel S, Pérès S, Woehrlé F. Efficacy of different treatment regimens of marbofloxacin in canine visceral leishmaniasis: a pilot study. Vet Parasitol. 2008;153(3-4):244-54.

28. Prefeitura da Cidade do Rio de Janeiro. Leishmaniose visceral [Internet]. Rio de Janeiro [citado 20 Abr 2021]. Disponível em: http://www.rio.rj.gov.br/web/vigilanciasanitaria/leishmaniose

29. Mancianti F, Gramiccia M, Gradoni L, Pieri S. Studies on canine leishmaniasis control. 1. Evolution of infection of different clinical forms of canine leishmaniasis following antimonial treatment. Trans R Soc Trop Med Hyg [Internet]. 1988 [citado 20 Abr 2021];82(4):566-7. doi: 10.1016/0035-9203(88)90510-x. Disponível em: https://www.sciencedirect.com/science/article/abs/pii/003592038890510X 


\section{ANEXO 1:}

1- Qual a sua idade?

2- Qual estado você mora?

3- Qual(is) os método(s) diagnóstico(s) laboratorial(is) utilizado(s)? escarificação; punção aspirativa; impressão por aposição ou biópsia de lesão cutâneas ou órgãos linfáticos; Citologia; Histopatológico; Isolamento do parasita; PCR; RIFI; ELISA

4- Caso diagnóstico positivo, comunica para as autoridades?

5- Caso positivo: Tratamento; Eutanásia; Outros

6- Caso seja realizado tratamento, qual a escolha?

Alopurinol; Anfotericina B; Antimoniais pentavalentes (Antimoniato de N-metil-glucamina ou estibogluconato de sódio); Marbofloxacina; Aminosidina; Miltefosina; Tratamento suporte de acordo com sintomas (Fluidoterapia, vitaminas, antibióticos); Outros.

7- São recomendadas como ações preventivas:

Utilização de coleiras de Deltametrina; Inseticidas; Telagem de janelas; Vacinação de animais contactantes

8- Caso seja realizada vacinação dos animais, qual vacina comercial de escolha?

Leish-Tec ${ }^{\circledR}$; Leishmune $\AA$; Não recomendo

9- No seu local de trabalho possui vacina disponível?

10- Em relação aos tutores: há seleção de acordo com seu nível socioeconômico para realizar o tratamento?

11- Em relação aos tutores: há seleção de acordo com sua responsabilidade e presença nas consultas?

12- Em relação aos animais infectados: são realizadas consultas periódicas em animais em tratamento?

13- Se sim, com qual frequência?

14- Em relação aos animais infectados: são realizados exames laboratoriais como acompanhamento?

Função renal; Função hepática; Hemograma completo; Pesquisa parasitológica; Não

Recebido em: 19/11/2020

Aceito em: 22/06/2021

Moustapha NA, Magdanelo ELLH, Multari JN, Tellaroli G, Santos, EW. Abordagem da leishmaniose visceral canina (LVC) por médicos veterinários. Vet. e Zootec. 2021; v28: 001-012. 